\title{
MAGE-A genes as predictors of the outcome of laryngeal squamous cell carcinoma
}

\author{
SHENGHUI LIU ${ }^{1,2}$, YAN ZHAO ${ }^{1}$, YURU XU ${ }^{1}$, MEIXIANG SANG ${ }^{2,3}$, \\ RUILI ZHAO ${ }^{1}$, LINA GU ${ }^{2}$ and BAOEN SHAN ${ }^{2,3}$ \\ ${ }^{1}$ Department of Otolaryngology; ${ }^{2}$ Research Center; ${ }^{3}$ Tumor Research Institute, \\ The Fourth Hospital of Hebei Medical University, Shijiazhuang, Hebei 050017, P.R. China
}

Received August 29, 2019; Accepted June 29, 2020

DOI: $10.3892 / \mathrm{ol} .2020 .11920$

\begin{abstract}
Laryngeal squamous cell carcinoma (LSCC) is one of the most common malignant tumors in the head and neck area. Melanoma-associated antigens A (MAGE-A) are strictly tumor-specific and are expressed in several types of tumors. To date, no studies have reported the potential of $M A G E-A$ genes as markers for circulating tumor cells (CTCs) in patients with LSCC. The present study aimed to evaluate the expression and the possible prognostic significance of $M A G E-A$ in the peripheral blood of patients with LSCC. In the present study, the expression of $M A G E-A$ genes was determined by multiplex semi-nested PCR and restriction endonuclease treatment of the peripheral blood of patients with LSCC. The association between $M A G E-A$ gene expression and clinicopathological parameters and prognosis was evaluated. The results demonstrated that the expression of $M A G E-A$ was associated with the predictors that indicate poor prognosis. The expression levels of $M A G E-A$ and each individual $M A G E-A$ gene were also associated with a shorter overall survival time of patients with LSCC. In conclusion, the results of the present study suggested that the expression of $M A G E-A$ genes may be a potential prognostic marker for patients with LSCC.
\end{abstract}

\section{Introduction}

Cancer is a major public health problem in China. Laryngeal squamous cell carcinoma (LSCC) is the most common malignant disease of the head and neck area, and is responsible for $99 \%$ of primary laryngeal carcinoma worldwide (1). Due to the increasing incidence rate (7 cases/100,000) (2), LSCC has gradually caused extensive concern among researchers and medical professionals for intensified research $(3,4)$ and clinical

Correspondence to: Dr Baoen Shan, Research Center, The Fourth Hospital of Hebei Medical University, 12 Jiankang Road, Shijiazhuang, Hebei 050017, P.R. China

E-mail: baoenshan@hotmail.com

Key words: laryngeal squamous cell carcinoma, prognostic marker, melanoma-associated antigen A, prognosis trials (5-8). Although surgery combined with chemoradiotherapy has significantly improved the survival rate of patients (5-year survival rate is 63\%) (2), recurrence and metastasis are still common and the prognosis remains poor, particularly in patients at the advanced stage. Therefore, the discovery of novel specific markers for early diagnosis and prognosis is urgently needed to improve patient survival.

Melanoma-associated antigen (MAGE), which was first discovered by Van der Bruggen (9) and termed MAGE-I, is a group of well-differentiated members of cancer/testicular antigens (CTA) (9). Thus far, 60 members of MAGE have been discovered and investigated (10). The MAGE gene family encodes tumor antigens recognized by autologous cytotoxic $\mathrm{T}$ lymphocytes $(11,12)$. Based on the difference in gene expression and genetic structure, the $M A G E$ family is categorized into two subfamilies, MAGE-I (MAGE-A, MAGE-B and $M A G E-C)$ and MAGE-II $(M A G E-D)(13)$. The most widely studied gene is $M A G E-A$, which is strictly tumor-specific, and includes 12 family members, termed MAGE-A1-12 (13). $M A G E-A$ is expressed in several types of tumors, such as breast and gastric cancer as well as glioma $(12,14)$.

The expression of $M A G E-A$ genes in the peripheral blood of patients with LSCC remains unclear. Due to the high similarity in the sequences of $M A G E-A 1,-A 2,-A 3,-A 4$ and- $A 6$, it is difficult to design a unique primer to detect the different genes. In order to investigate the expression of the MAGE-A family genes in the peripheral blood of patients with LSCC and its association with prognosis, multiple $M A G E-A$ genes in the peripheral blood of 104 patients with LSCC and 30 healthy volunteers were detected by multiple nested reverse transcription (RT)-PCR and restriction endonuclease treatment. The aim of the present study was to explore whether the expression of $M A G E-A \mathrm{~s}$ in the peripheral blood circulating tumor cells (CTCs) may be used as a biomarker for guiding clinical treatment and monitoring prognosis in patients with LSCC.

\section{Materials and methods}

Patients and clinical parameters. A total of 104 patients with LSCC were recruited from the Department of Otolaryngology, The Fourth Hospital of Hebei Medical University between June 2011 and June 2012. In addition, 30 healthy volunteers with no history of carcinoma were enrolled in the present 
study during the same period. None of the patients underwent chemotherapy or radiotherapy prior to surgery. Written informed consent was provided by all participants before enrollment. The study protocol was approved by the Medical Ethics Committee of The Fourth Hospital of Hebei Medical University (approval no. 2011KY112).

The clinicopathological data of the patients were retrospectively collected, including age, smoking history, tumor size, clinical stage (8th edition of the American Joint Committee on Cancer) (15), clinical classification, pathological degree and lymph node metastasis.

Blood and tissue sample collection. Fresh blood samples $(5 \mathrm{ml})$ were collected from the patients before surgery, as well as from the volunteers. All blood samples were immediately stored at $4^{\circ} \mathrm{C}$, and RNA extraction was performed on the day of sample collection. Blood samples were processed within 1 to $4 \mathrm{~h}$ after collection. Blood samples of healthy volunteers were used as the negative control for the RT-PCR assay.

Normal testicular tissue samples were collected from two patients undergoing castration at the Department of Urinary Surgery, The Fourth Hospital of Hebei Medical University. Written informed consent was provided by the two patients. The samples were stored at $-80^{\circ} \mathrm{C}$ until subsequent experiments.

RNA extraction and cDNA synthesis. Red blood cell lysis buffer was used to collect the peripheral blood cells. Total RNA was extracted from the peripheral blood cells and tissues using TRIzol ${ }^{\circledR}$ reagent (Invitrogen; Thermo Fisher Scientific, Inc.) according to the manufacturer's instructions. Ultraviolet spectrophotometry and agarose gel electrophoresis were used to determine the quality of the RNA. The isolated RNA was stored at $-80^{\circ} \mathrm{C}$. RNA $(2 \mu \mathrm{g})$ was used to synthesize the first-strand cDNA using the RevertAid First Strand cDNA Synthesis kit (Fermentas; Thermo Fisher Scientific, Inc.) at $42^{\circ} \mathrm{C}$ for $1 \mathrm{~h}$.

$R T$-PCR. cDNA was used for PCR amplification by using Go Taq Green Master Mix (Promega Corporation) with primers for the MAGE-A9 and MAGE-Al1 genes. RNA integrity was confirmed by performing PCR amplification with the primer for the GAPDH gene. Agarose gel electrophoresis (2\%) was used to identify the RT-PCR products, and the bands were observed under ultraviolet light. Each sample were measured three times. GAPDH was used as the internal reference gene. The primer sequences, product lengths, PCR cycle conditions, initial denaturation and final extension steps are presented in Table I.

Multiplex semi-nested PCR. GoTaq ${ }^{\circledR}$ Green Master mix (Promega Corporation) was used to amplify the cDNA. In the first cycle of PCR, the reaction mixture comprised $5 \mu \mathrm{l}$ cDNA product of the reverse transcription, $0.5 \mu 1$ MAGE-F1 $(10 \mu \mathrm{M}), 1 \mu 1 \mathrm{MAGE}-\mathrm{R} 1(10 \mu \mathrm{M}), 0.2 \mu 1 \mathrm{MAGE}-\mathrm{F} 2(10 \mu \mathrm{M})$, $0.2 \mu \mathrm{l}$ MAGE-R2 (10 $\mu \mathrm{M}), 25 \mu \mathrm{l} 2 \mathrm{X}$ PCR Master mix and deionized water added up to $50 \mu \mathrm{l}$. In the second cycle of PCR, the reaction mixture comprised $5 \mu \mathrm{l}$ external PCR product, $0.5 \mu$ l MAGE-F3 $(10 \mu \mathrm{M}), 1 \mu 1$ MAGE-R3 $(10 \mu \mathrm{M})$, $0.2 \mu \mathrm{l}$ MAGE-F4 $(10 \mu \mathrm{M}), 0.2 \mu \mathrm{l}$ MAGE-R4 $(10 \mu \mathrm{M}), 50 \mu \mathrm{l}$
2X PCR Master mix and deionized water added up to $100 \mu \mathrm{l}$. The primers are presented in Table II. GAPDH was used as the internal reference gene. The thermocycling conditions were as follows: (1) $95^{\circ} \mathrm{C}$ for $5 \mathrm{~min}$; (2) 32 cycles of $95^{\circ} \mathrm{C}$ for $45 \mathrm{sec}, 65^{\circ} \mathrm{C}$ for $45 \mathrm{sec}$ and $72^{\circ} \mathrm{C}$ for $90 \mathrm{sec}$ and 31 cycles of (2); (3) $72^{\circ} \mathrm{C}$ for $6 \mathrm{~min}$. PCR product $(6 \mu \mathrm{l})$ was used for electrophoresis on a $1.5 \%$ agarose gel. The amplification results were observed in the gel imaging system (Syngene Inc.).

Restriction endonuclease treatment. The products of multiplex semi-nested PCR were purified using the QIAquick PCR Product Purification kit (Qiagen China Co., Ltd.) according to the manufacturer's instructions. The purified products were digested by restriction endonucleases $B c l \mathrm{I}, S p h \mathrm{I}, E c o R \mathrm{I}$, Eco47III and AfIIII, and gene fragments of MAGE-A1, -A2, $-A 3,-A 4$ and $-A 6$ were obtained, respectively (Table III). The restriction fragment $(6 \mu \mathrm{l})$ was analyzed by electrophoresis using a 1.5\% agarose gel. The bands were observed in the gel imaging system.

Statistical analysis. SPSS v20.0 software (IBM Corp.) was used to analyze the data. The display strip is defined as high expression group and vice versa. $\chi^{2}$ or Fisher's exact test were used to evaluate the potential association between the expression of all $M A G E-A$ genes or single $M A G E-A$ genes and patient clinicopathological characteristics. The Kaplan-Meier method was used to estimate the overall survival time of patients with LSCC. The Cox regression model was used for univariate and multivariate analysis of overall survival and prognostic factors. $\mathrm{P}<0.05$ was considered to indicate a statistically significant difference.

\section{Results}

Expression of MAGE-A genes in the peripheral blood of patients with LSCC and healthy donors. Multiplex semi-nested RT-PCR and RT-PCR were used to detect the expression of MAGE-A genes, including MAGE-Al, -A2, $-A 3,-A 4,-A 6,-A 9$ and $-A 11$, in two normal testicular tissue samples (Fig. 1A). As the MAGE-A gene belongs to the $C T A$ gene family, it is only expressed in normal testis and other germ cells, but not in other normal tissues (9). Therefore, testicular tissue was used in the present study as a positive control. Subsequently, the expression of MAGE-A in the blood samples of 104 patients with LSCC and 30 healthy donors was examined. The representative samples of the control and $M A G E-A$ products in the peripheral blood of healthy donors (negative control) and patients with LSCC, as well as normal testicular tissue (positive control) are presented in Fig. 1A. The MAGE-A product was observed in the normal testicular tissues and in the blood samples of a number of patients with LSCC, but not in the blood samples from the healthy donors. The representative LSCC blood samples with positive $M A G E-A$ gene expression after internal PCR (second PCR cycle) are presented in Fig. 1B.

As presented in Fig. 2, 31 of 104 patients with LSCC (29.8\%) exhibited MAGE-A gene expression in the peripheral blood. The expression of MAGE-A9 and -A11 mRNA was detected by RT-PCR, whereas the expression pattern of other individual MAGE-A genes was identified by restriction 
Table I. Primer sequences for reverse transcription-PCR.

\begin{tabular}{|c|c|c|c|c|}
\hline Gene & Primer sequences $\left(5^{\prime} \rightarrow 3^{\prime}\right)$ & PCR cycle conditions & No. of cycles & PCR product length, bp \\
\hline MAGE-A9 & $\begin{array}{l}\text { F: GTCTCTCGAGCAGAGGAGTCCGC } \\
\text { R: CTCAGCCACCTTCAATTTCAGT }\end{array}$ & $95^{\circ} \mathrm{C} 30 \mathrm{sec} ; 58^{\circ} \mathrm{C} 30 \mathrm{sec}, 72^{\circ} \mathrm{C} 45 \mathrm{sec}$ & 35 & 340 \\
\hline MAGE-A11 & $\begin{array}{l}\text { F: ATGGAGACTCAGTTCCGAGA } \\
\text { R: AAGAACTTTCATCTTGCTGG }\end{array}$ & $95^{\circ} \mathrm{C} 30 \mathrm{sec}, 52^{\circ} \mathrm{C} 30 \mathrm{sec}, 72^{\circ} \mathrm{C} 45 \mathrm{sec}$ & 35 & 878 \\
\hline GAPDH & $\begin{array}{l}\text { F: ACCTGACCTGCCGTCTAGAA } \\
\text { R: TCCACCACCCTGTTGCTGTA }\end{array}$ & $95^{\circ} \mathrm{C} 15 \mathrm{sec}, 58^{\circ} \mathrm{C} 15 \mathrm{sec}, 72^{\circ} \mathrm{C} 20 \mathrm{sec}$ & 28 & 247 \\
\hline
\end{tabular}

MAGE, melanoma-associated antigen; F, forward; R, reverse.

Table II. Primer sequences for multiplex semi-nested PCR.

\begin{tabular}{lll}
\hline Gene & \multicolumn{1}{c}{ Primer sequences $\left(5^{\prime} \rightarrow 3\right.$ ') } & Fragment length, bp \\
\hline MAGE-As first cycle & F1: ACTGGCCCTGGCTGCAAC & 993 \\
& R1: GCCCTGACCAGAGTCATCAT & \\
& F2: ACTGGCCTTGGCTGCAAC & 965 \\
MAGE-As second cycle & R2: CGAGAGTCATCATG \\
& F3: ACTGGCCCTGGCTGCAAC & R3: AGGCCCTGGGCCTGGTG \\
& F4: ACTGGCCTTGGCTGCAAC \\
GAPDH & R4: AGGCCCTGGGCTTGGTG \\
& F: ACCTGACCTGCCGTCTAGAA & 247 \\
\hline
\end{tabular}

MAGE, melanoma-associated antigen; F, forward; R, reverse.

Table III. Restriction endonuclease mixtures, multi-MAGE-A products and restriction fragments for each tested MAGE-A gene.

\begin{tabular}{lccc}
\hline Restriction endonuclease & MAGE gene & PCR product length, bp & Fragment length, bp \\
\hline BclI & A1 & 893 & 106,787 \\
SphI & A2 & 914 & $21,22,151,720$ \\
EcoRI & A3 & 914 & 167,747 \\
Eco47III & A4 & 917 & 375,542 \\
AflIII & A6 & 914 & $22,172,282,438$ \\
\hline
\end{tabular}

MAGE, melanoma-associated antigen.

endonuclease treatment. $M A G E-A 1$ expression was positive in 19 of $104(18.3 \%), M A G E-A 2$ expression was positive in 21 of $104(20.2 \%), M A G E-A 3$ expression was positive in 21 of $104(20.2 \%), M A G E-A 4$ expression was positive in 16 of $104(15.4 \%), M A G E-A 6$ expression was positive in 12 of 104 (11.5\%), MAGE-A9 expression was positive in 27 of 104 (26.0\%) and MAGE-A11 expression was positive in 29 of 104 (27.9\%) patients with LSCC. The frequency of individual $M A G E$ - $A$ gene expression was in the following order: A11 > $\mathrm{A} 9>\mathrm{A} 2=\mathrm{A} 3>\mathrm{A} 1>\mathrm{A} 4>\mathrm{A} 6$. A total of 18 patients were positive for only one $M A G E$-A gene, 12 patients were positive for two genes, seven patients were positive for three genes, eight patients were positive for four genes, eight patients were positive for five genes and two patients were positive for six genes. The genomic information of MAGE-A1-12 for all 104 patients with LSCC is presented in Table SI.

Fig. 3 demonstrates the expression of the $M A G E-A$ gene products from two patients following restriction endonuclease treatment. A multiple $M A G E$-As product was observed in the peripheral blood of patients no. 17 and 45. Subsequently, the $M A G E-A$ product (second PCR cycle) was digested with $B c l$, SphI, EcoRI, Eco47III and $A f I \mathrm{III}$, and the digested products were separated by agarose gel electrophoresis. The individual $M A G E-A$ genes were identified by observing the fragment pattern. For patient 17 (Fig. 3A), the fragments of $787 \mathrm{bp}$ was observed after $B c l$ I digestion, 720 bp was observed after 


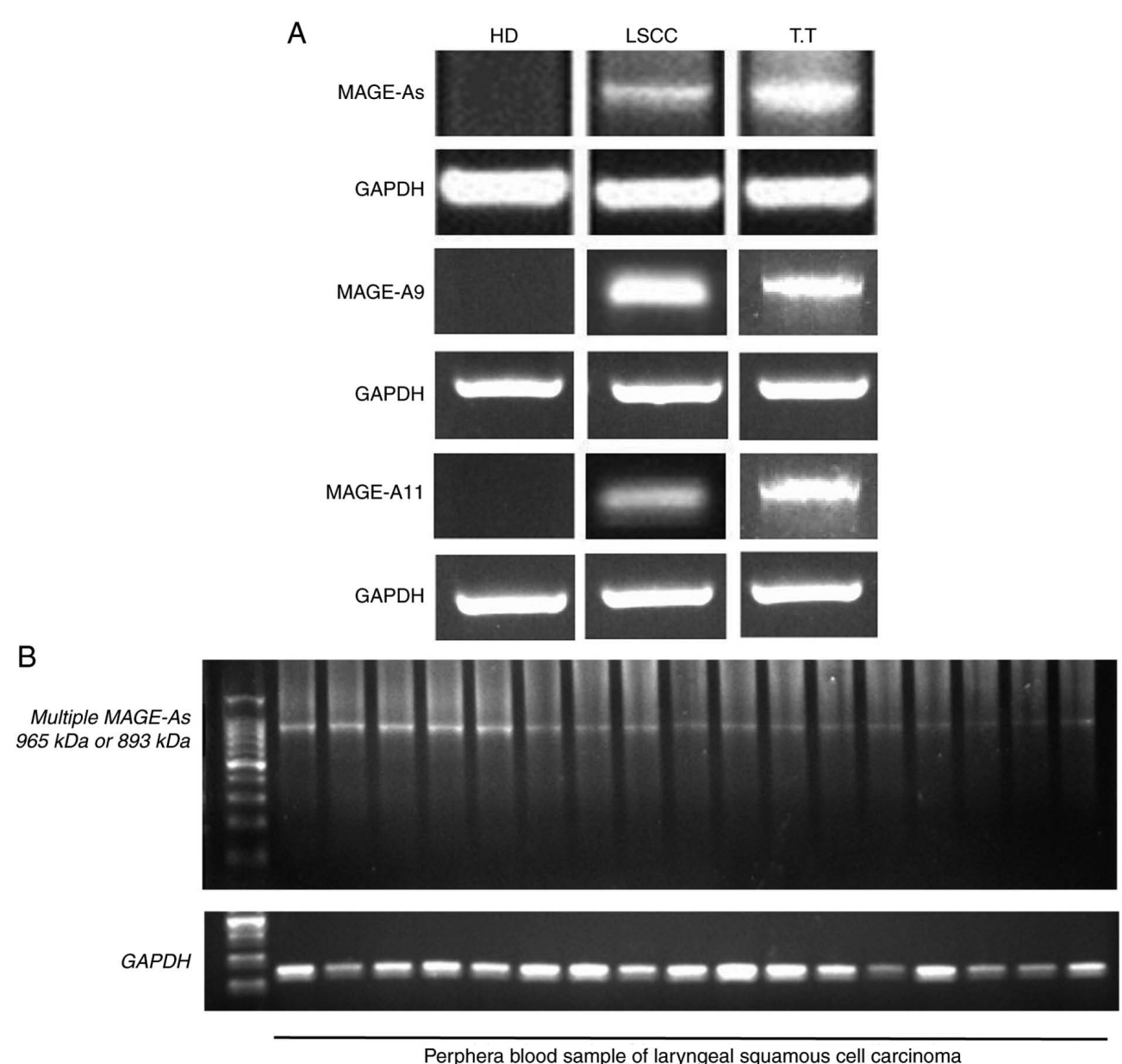

Figure 1. Expression of MAGE-A mRNA measured by reverse transcription-PCR in the peripheral blood of patients with LSCC and healthy volunteers. (A) Representative blots of multiple MAGE-As and GAPDH control products in the blood samples of patients with LSCC and healthy volunteers, as well as in normal testicular tissues. (B) Representative samples with positive MAGE-A gene products of the internal PCR (second PCR cycle) in patients with LSCC. MAGE, melanoma-associated antigen; LSCC, laryngeal squamous cell carcinoma; HD, healthy donor; T.T, normal testicular tissue.

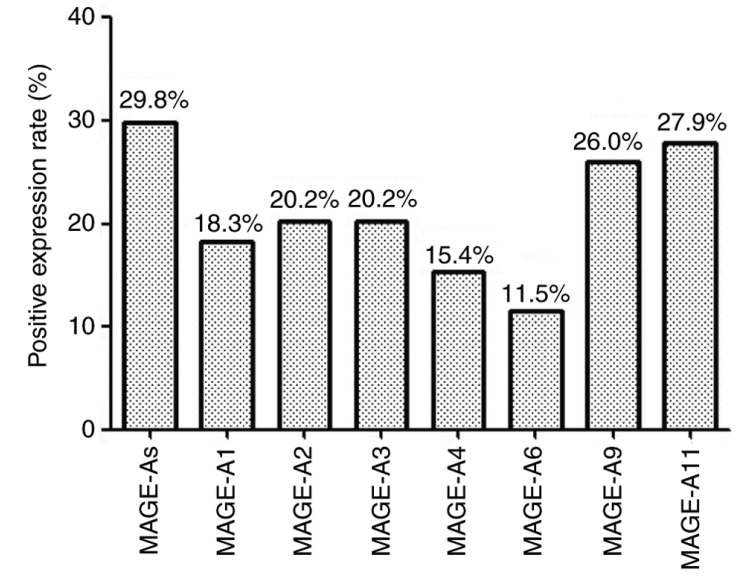

Figure 2. Expression patterns of MAGE-A1, -A2, -A3, -A4, -A6, -A9 and -A11 in the peripheral blood of patients with LSCC. MAGE, melanoma-associated antigen; LSCC, laryngeal squamous cell carcinoma.

SphI digestion, 747 bp was observed after EcoRI digestion, and $438 \mathrm{bp}$ was observed after $A f I I I I$ digestion, indicating the presence of $M A G E-A 1,-A 2,-A 3$ and $-A 6$ in the PCR product. The expression pattern of $M A G E-A s$ in patient 45 is presented in Fig. 3B; the expression of MAGE-Al and $-A 6$ was not observed, but the 720 bp band was observed after $S p h$ I digestion, and the fragment of $747 \mathrm{bp}$ was observed after EcoRI digestion, indicating the presence of $M A G E-A 2$ and $-A 3$ in the PCR product.

Association between MAGE-A gene expression in the peripheral blood and the clinicopathological characteristics of patients with LSCC. The association between MAGE-A gene expression in the peripheral blood and the clinicopathological characteristics of patients with LSCC was evaluated (Table IV). The expression of MAGE-A genes (MAGE-As, $-A 1,-A 2,-A 3,-A 4,-A 6,-A 9$ and $-A 11)$ were not associated with age, smoking history, tumor size and location, but was positively associated with lymph node metastasis $(\mathrm{P}=0.001$, $\mathrm{P}=0.022, \mathrm{P}<0.001, \mathrm{P}=0.001, \mathrm{P}=0.016, \mathrm{P}<0.001, \mathrm{P}=0.001$ and $\mathrm{P}=0.016$, respectively). High expression levels of $M A G E-A s$ in LSCC were associated with the histological degree $(\mathrm{P}=0.007)$. Among individual $M A G E-A s$, positive $M A G E-A 1,-A 3$, $-A 4$ and $-A 6$ expression was more frequent in patients with histological grade $\mathrm{G} 3$ compared with those with histological grades $\mathrm{G} 1 / \mathrm{G} 2(\mathrm{P}=0.005, \mathrm{P}=0.013, \mathrm{P}=0.001$ and $\mathrm{P}=0.001$, respectively). In addition, more frequent positive expression of MAGE-A3, -A6, -A9 and -A11 was observed in patients 
A

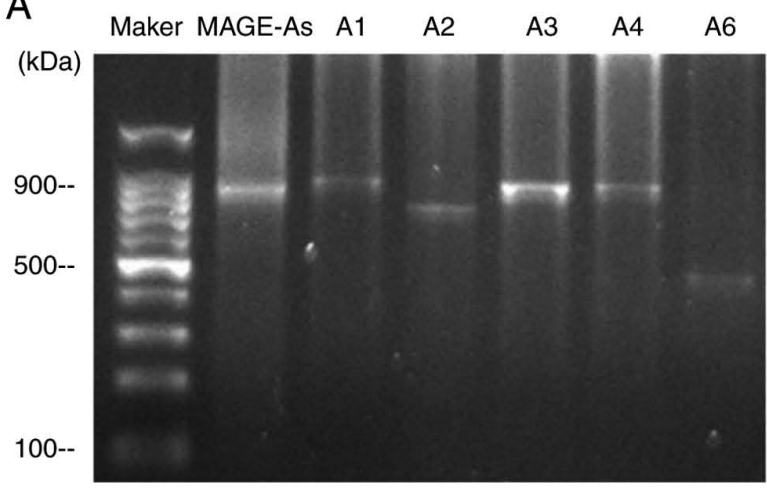

B

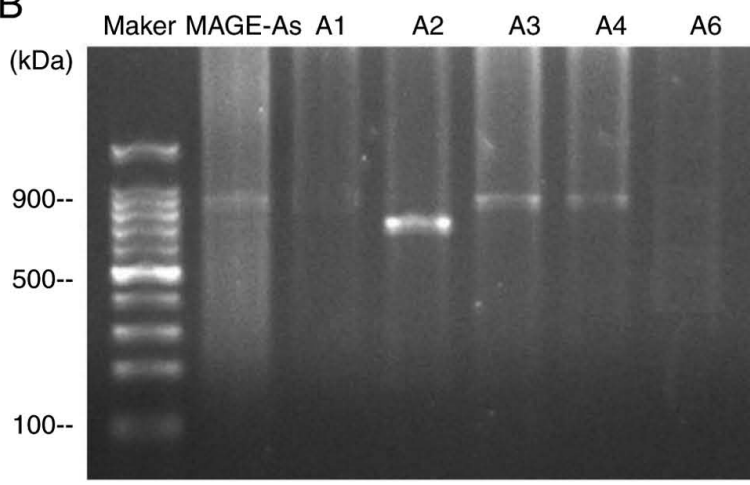

Figure 3. MAGE-A1, -A2, -A3, -A4 and-A6 expression in the peripheral blood of patients with LSCC no. (A) 17 and (B) 45. MAGE, melanoma-associated antigen; LSCC, laryngeal squamous cell carcinoma.

with high clinical stage compared with that in patients with low clinical stage $(\mathrm{P}=0.044, \mathrm{P}=0.048, \mathrm{P}=0.01$ and $\mathrm{P}=0.045$, respectively). No associations were observed between each individual $M A G E-A$ genes expression and other clinicopathological factors.

Association between MAGE-A gene expression in the peripheral blood and the overall survival of patients with LSCC. All 104 patients with LSCC were followed up for 18-65 months. Kaplan-Meier analysis was performed to determine the association between $M A G E-A$ gene $(M A G E-A 1,-A 2,-A 3$, $-A 4,-A 6,-A 9$ and $-A 11)$ expression levels and the overall survival of patients with LSCC. Overall survival of patients with high $M A G E-A$ gene expression in the peripheral blood was significantly lower compared with those with low expression $(\mathrm{P}=0.020, \mathrm{P}=0.061, \mathrm{P}=0.010, \mathrm{P}=0.036, \mathrm{P}=0.039, \mathrm{P}<0.001$, $\mathrm{P}<0.001$ and $\mathrm{P}<0.001$, respectively; Fig. 4). To further evaluate the prognostic significance of $M A G E-A$ expression, univariate analysis of clinicopathological factors and overall survival was performed. High expression of MAGE-As $(\mathrm{P}=0.024),-A 2 \quad(\mathrm{P}=0.014),-A 3 \quad(\mathrm{P}=0.041),-A 4 \quad(\mathrm{P}=0.046)$, -A6 $(\mathrm{P}<0.001),-A 9(\mathrm{P}<0.001)$ and $-A 11(\mathrm{P}<0.001)$, as well as lymph node metastasis $(\mathrm{P}<0.01)$, low clinical stage $(\mathrm{P}=0.013)$ and high histological grade $(\mathrm{P}=0.028)$ were demonstrated to be predictors of poor overall survival (Table V). clinical stage, which includes tumor size and lymph node metastasis, and $M A G E-A \mathrm{~s}$, which includes $M A G E-A 1,-A 2,-A 3,-A 4$ and $-A 6$, were not considered as independent prognostic factors. Lymph node metastasis, histological grade and the expression of $M A G E-A 2,-A 3,-A 4,-A 6,-A 9$ and $-A 11$ were further analyzed by multivariate Cox regression analysis. As demonstrated in Table V, high expression of $M A G E-A 11(\mathrm{P}=0.032)$ and lymph node metastasis $(\mathrm{P}<0.01)$ were determined to be independent prognostic factors for poor prognosis of patients with LSCC.

\section{Discussion}

Clinical imaging is often the first to identify the tumor and is important for the diagnosis of recurrence and metastasis of the auxiliary technology (2). Failure to identify the primary or metastatic tumors by imaging means that the best time for diagnosis and treatment is missed, and late metastasis of the tumor has no effective treatment and the prognosis is poor (2). The process by which tumor cells invade the body remains unclear and may involve the active invasion of cells via epithelial-to-mesenchymal transition (16) and passively shed individual cells or clusters of tumor cells from impaired tumor blood vessels $(17,18)$. The presence of CTCs in the peripheral blood is considered to be the key factor of tumor metastasis (19). A number of studies have evaluated the clinical application value of CTCs for metastatic breast $(20,21)$, prostate (22), colon (23) and lung $(24,25)$ cancer. Using the FDA-approved Cell Search system (Veridex), the peripheral blood CTC count test and analysis of the prognosis of patients suggest that CTCs can be used as an independent prognostic indicator $(26,27)$. The technology detects the biomarkers on the cell surface to identify the CTCs $(26,27)$. The downregulation or absence of epithelial markers should have an effect on detecting CTCs (19). Thus, the discovery of new tumor markers may help identify CTCs in the peripheral blood of patients with malignant tumors.

RT-PCR, which has a wide range of applications, is considered the most sensitive method for detecting CTCs in the peripheral blood (28). However, the following issues may exist: i) Large amounts of water in the peripheral blood may dilute the normal mRNA and cause false negative results (29); ii) contamination of the target gene in the peripheral blood, leading to DNA amplification, may result in false positive results (30), and iii) low levels of abnormal transcription and amplification of target genes in the peripheral blood tumor cells may also cause false-positive results (30). Improving the detection technology, designing more suitable primers and selecting accurate tumor markers may help avoid the aforementioned issues. Previous studies have used RT-nested PCR to detect the mRNA expression of CTCs in the peripheral blood of non-cancerous and colorectal cancer cells, and demonstrated high sensitivity and specificity $(31,32)$. It has been demonstrated that the expression of $M A G E-A$ genes can be used as a biomarker of CTCs in colorectal, breast and gastric cancer (33). The results of the previous study demonstrated that the MAGE-A antigen is a tumor-associated antigen of LSCC (34). Therefore, $M A G E-A$ mRNA may be used to detect CTCs in the peripheral blood of patients with LSCC as a specific tumor marker, which may guide the diagnosis and prognosis of LSCC. In the present study, fresh blood was used for further analysis of $M A G E-A$ gene expression; 


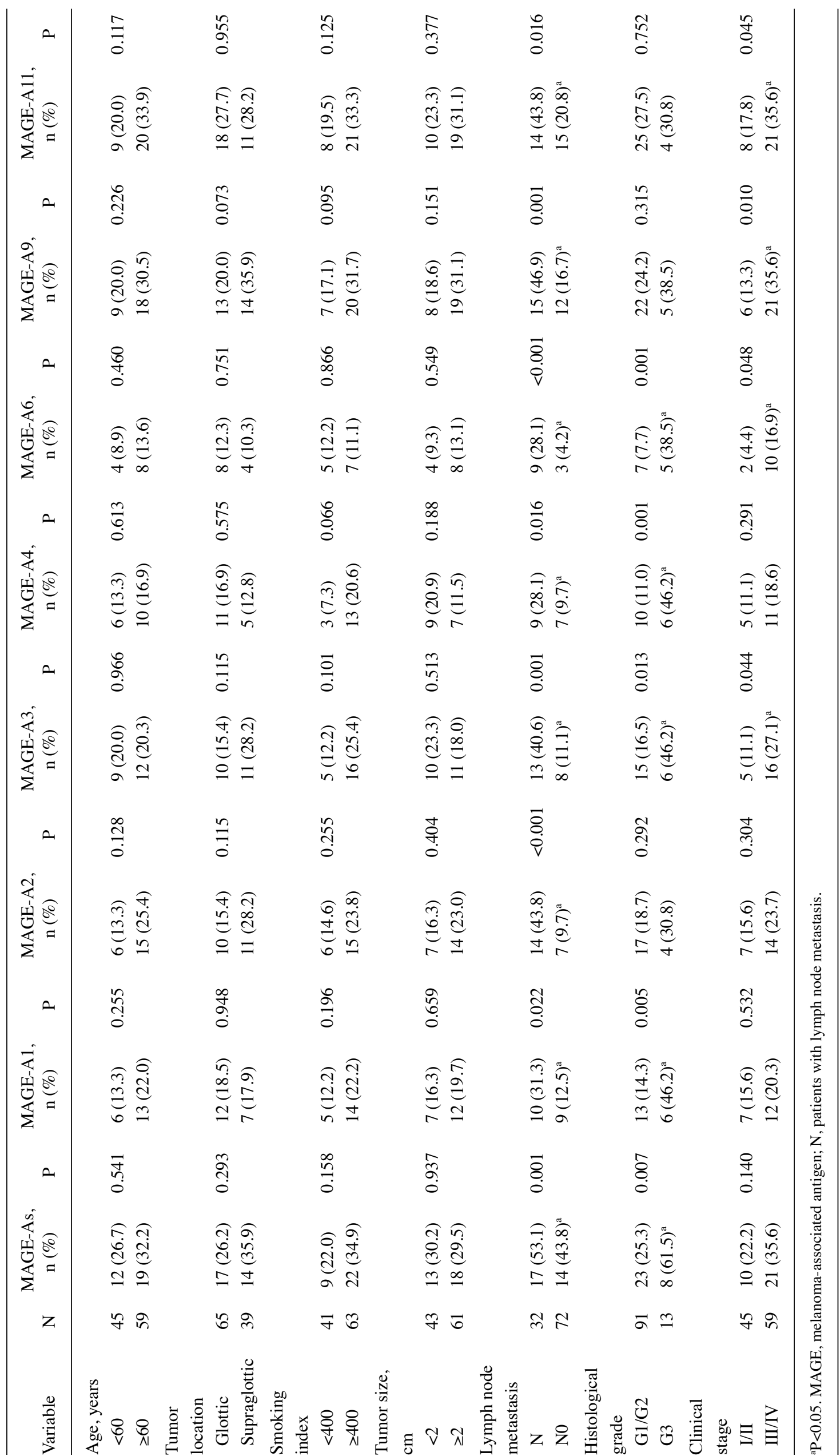


Table V. Univariate and multivariate analyses of prognostic factors for overall survival of patients with laryngeal squamous cell carcinoma.

\begin{tabular}{|c|c|c|c|c|c|c|}
\hline \multirow[b]{2}{*}{ Variables } & \multicolumn{3}{|c|}{ Univariate analysis } & \multicolumn{3}{|c|}{ Multivariate analysis } \\
\hline & HR & P-value & $95 \% \mathrm{CI}$ & HR & P-value & $95 \% \mathrm{CI}$ \\
\hline Expression of MAGE-As, high vs. low & 2.048 & $0.024^{\mathrm{a}}$ & $1.099-3.816$ & & & \\
\hline Expression of MAGE-A1, high vs. low & 1.948 & 0.068 & $0.951-3.990$ & & & \\
\hline Expression of MAGE-A2, high vs. low & 2.297 & $0.014^{\mathrm{a}}$ & $1.187-4.443$ & 2.137 & 0.050 & $1.001-4.561$ \\
\hline Expression of MAGE-A3, high vs. low & 2.016 & $0.041^{\mathrm{a}}$ & $1.028-3.954$ & 1.207 & 0.731 & $0.412-3.540$ \\
\hline Expression of MAGE-A4, high vs. low & 2.131 & $0.046^{\mathrm{a}}$ & $1.013-4.482$ & 2.339 & 0.174 & $0.686-7.970$ \\
\hline Expression of MAGE-A6, high vs. low & 4.050 & $<0.001^{\mathrm{a}}$ & $1.958-8.376$ & 1.410 & 0.480 & $0.543-3.665$ \\
\hline Expression of MAGE-A9, high vs. low & 3.204 & $<0.001^{\mathrm{a}}$ & $1.722-5.961$ & 2.082 & 0.065 & $0.954-4.543$ \\
\hline Expression of MAGE-A11, high vs. low & 3.019 & $<0.001^{\mathrm{a}}$ & $1.636-5.573$ & 2.438 & $0.032^{\mathrm{a}}$ & $1.080-5.504$ \\
\hline Age, years, $<60$ vs. $\geq 60$ & 1.369 & 0.327 & $0.730-2.566$ & & & \\
\hline Tumor location, supraglottic vs. glottic & 1.839 & 0.053 & $0.992-3.409$ & & & \\
\hline Smoking index, $<400$ vs. $\geq 400$ & 1.335 & 0.381 & $0.700-2.547$ & & & \\
\hline Tumor size, $\mathrm{cm},<2$ vs. $\geq 2$ & 1.924 & 0.057 & $0.981-3.777$ & & & \\
\hline Histological grade, G1/G2 vs. G3 & 2.013 & $0.028^{\mathrm{a}}$ & $1.078-3.760$ & 1.290 & 0.544 & $0.568-2.931$ \\
\hline Clinical stage (AJCC), I/II vs. III/IV & 2.345 & $0.013^{\mathrm{a}}$ & $1.194-4.604$ & & & \\
\hline Metastatic state of lymph node, $\mathrm{N}$ vs. NO & 10.788 & $<0.001^{\mathrm{a}}$ & $5.036-23.110$ & 21.112 & $<0.001^{\mathrm{a}}$ & $7.927-56.226$ \\
\hline
\end{tabular}

${ }^{a} \mathrm{P}<0.05$. MAGE, melanoma-associated antigen; HR, hazard ratio; CI, confidence interval; N, patients with lymph node metastasis; AJCC, American Joint Committee on Cancer.

A
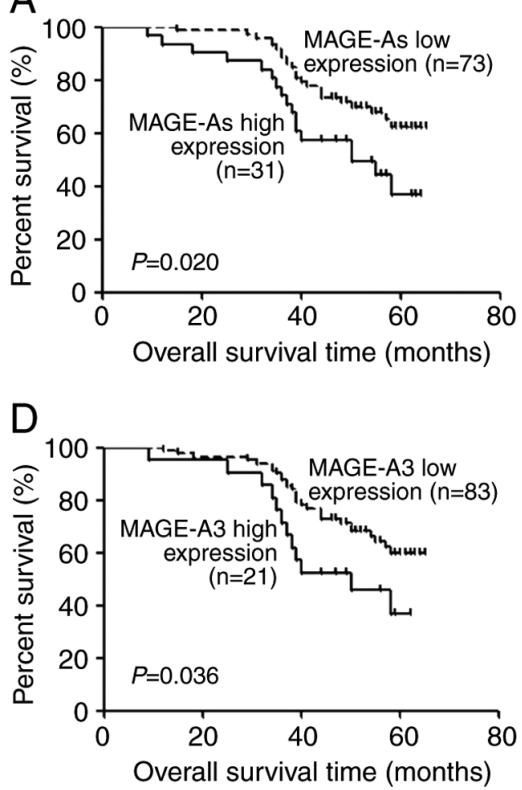

B

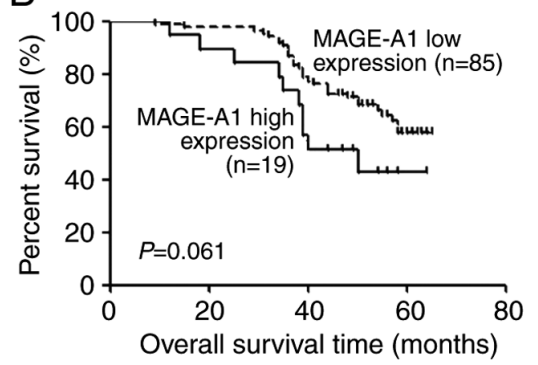

E

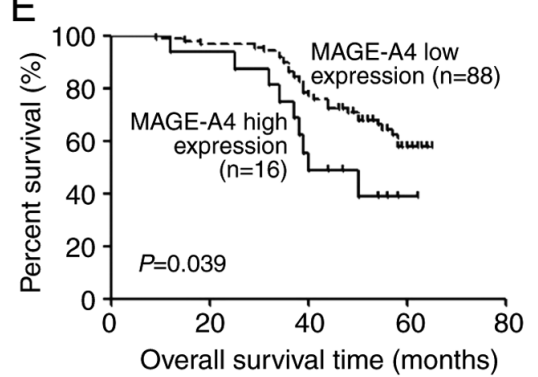

C

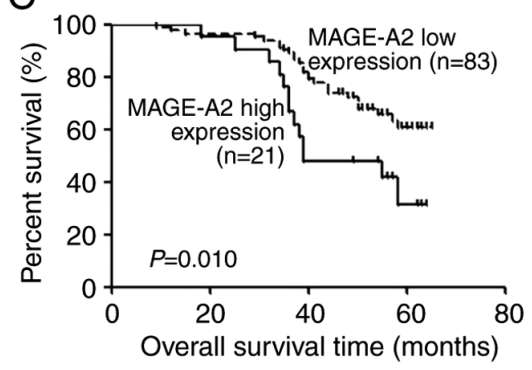

$\mathrm{F}$

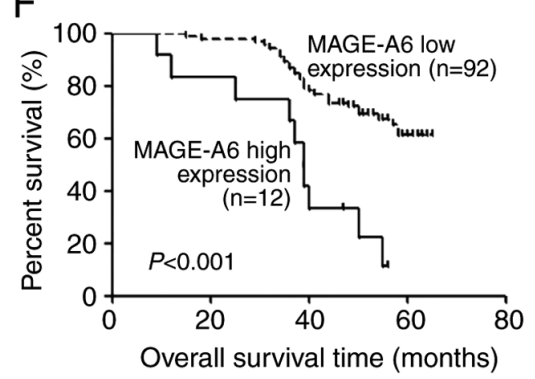

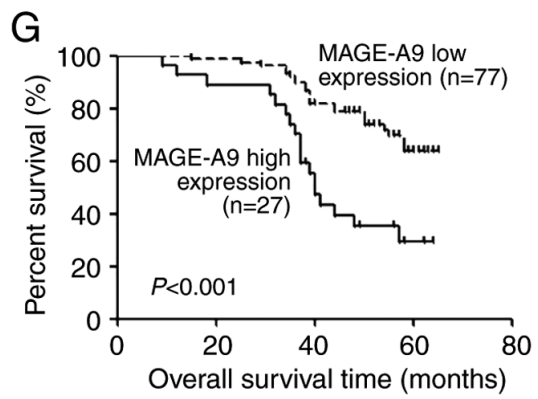

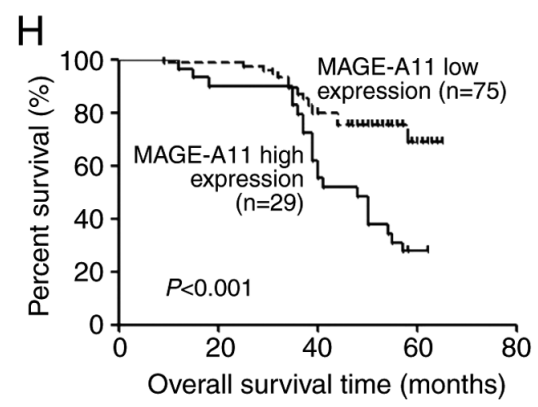

Figure 4. Kaplan-Meier curve analysis of the associations between (A) MAGE-As, as well as (B-H) each MAGE-A member and the 5-year overall survival rate of patients with laryngeal squamous cell carcinoma. MAGE, melanoma-associated antigen. 
fresh blood is easy to collect and observe, allowing for timely guidance on clinical diagnosis and treatment.

Due to the high homology, it is difficult to design specific primers for a single $M A G E-A$ gene. Therefore, a pair of primer sequences containing two forward primers and two reverse primers were designed in the present study for the amplification of a mixture of $M A G E-A 1,-A 2,-A 3,-A 4$ and $-A 6$ genes by multi-RT-nested PCR. The expression of $M A G E-A 9$ and -A11 mRNA was detected by RT-PCR. MAGE-A mRNA was expressed in different degrees in peripheral blood of patients with LSCC, while $M A G E-A$ expression was not detected in the healthy donors. These are consistent with previous studies $(35,36)$. A total of 18 patients were positive for only one $M A G E-A$ gene, 12 patients were positive for two genes, seven patients were positive for three genes, eight patients were positive for four genes, eight patients were positive for five genes, and two patients were positive for six genes. Since the MAGE-A gene only exists in tumor cells (9), if MAGE-A gene expression is detected in peripheral blood, they must be expressed in tumor cells. In view of the definition of CTC, the results of the present study indicated that MAGE-A is expressed in CTCs. The results of the present study suggested that $M A G E-A$ mRNA was only expressed in tumor cells and may be detected only in the presence of tumor cells in the peripheral blood of patients with LSCC. Therefore, the expression of $M A G E-A$ genes may be used as a specific marker for detecting CTCs in the peripheral blood of patients with LSCC.

The association between MAGE-A gene expression in the peripheral blood and the clinicopathological features of patients with LSCC was statistically analyzed in the present study. The expression of $M A G E-A 1,-A 3,-A 4$ and -A6 were more frequently detected in patients with histological grade G3 tumors compared with patients with tumor grades G1/G2. A previous study has demonstrated that histological grade and tumor prognosis are significantly associated in breast cancer (37). Therefore, the expression of MAGE-A1, -A3, -A4 and $-A 6$ genes may be an important indicator of the prognosis of LSCC. In the present study, the expression of $M A G E-A 3$, $-A 6,-A 9$ and $-A 11$ was observed in patients with a high clinical stage more frequently compared with that in patients with a low clinical stage. Patients with late clinical staging usually have a poor prognosis (37). In addition, the expression of $M A G E-A$ s in the peripheral blood of patients with LSCC was positively associated with the lymph node metastasis status in the present study. For each individual MAGE-A gene, including $M A G E-A 1,-A 2,-A 3,-A 4,-A 6,-A 9$ and $-A 11$, the expression frequency in patients with lymph node metastasis was significantly higher compared with that in patients without lymph node metastasis. Previous studies have demonstrated that CTCs are commonly present in advanced metastatic malignancies, with more CTCs in the peripheral blood of distantly metastatic breast cancer compared with early-stage breast cancer (38), and similar observations in ovarian cancer (39). In the present univariate analysis, individual $M A G E-A$ expression, metastatic state of the lymph nodes, clinical stage and histological grade qualified to enter the regression model; however, as clinical stage includes the metastatic state of the lymph nodes and distant metastasis, only the metastatic state of the lymph nodes was entered into the regression model. The results demonstrated that multiple $M A G E-A s$ expression, the metastatic state of the lymph nodes and distant metastasis were risk factors for the 5-year survival of patients with LSCC.

To date, serological hallmark and high-resolution imaging technology still cannot identify micrometastasis and reflect the efficacy of treatments. CTCs detected in the peripheral blood suggest the possibility of early occult micrometastasis $(26,27)$. CTCs cannot only be used to study the biological characteristics of malignant tumors, but they overcome the disadvantage of traditional tissue biopsy and allow real-time dynamic monitoring of the changes in the tumor (40). Previous studies have demonstrated that the changes in the number of CTCs can reflect the efficacy of treatments and provide the basis for individual treatment. Qiao et al (41), reported the quantitative variation of CTCs in a patient with ESCC before and after surgery and during a 5-year follow-up period; the results demonstrated that the number of CTCs before and the initial period after surgery remained high. By contrast, following combined treatment, the number of CTCs deceased, and after 117 weeks, the number gradually stabilized at a low level (41). Thus, a change in the number of peripheral blood CTCs may be used to monitor disease status and treatment efficacy. Another previous study reported that clinically acquired drug resistance did not become resistant at the cellular level during the course of treatment, but clinically acquired drug resistance was the selective reaction of heterogeneous cancer cells to target cells (42). Through the dynamic supervision of certain molecular indicators of CTCs, the endpoint for therapy can be determined (43). CTCs in the peripheral blood of patients with LSCC can be examined to dynamically monitor the changes and development of the tumor in order to achieve an improved understanding of personalized therapy. CTCs in the peripheral blood of patients with LSCC may be monitored by detecting the $M A G E-A$ genes to guide clinical treatment and the judgement of prognosis.

In conclusion, the results of the present study identified the expression patterns of multiple $M A G E$ - $A$ genes in the peripheral blood of patients with LSCC. $M A G E-A$ gene expression in the peripheral blood may therefore be used as a molecular marker for guiding the treatment and monitoring the prognosis of patients with LSCC.

\section{Acknowledgements}

Not applicable.

\section{Funding}

This study was supported by the Financial Supporting Program of Hebei Province (grant no. 2014]1257), the Financial Department of Hebei Province (grant no. 2016]361006) and the Hebei Health Department (grant no. 20150786).

\section{Availability of data and materials}

The datasets used and/or analyzed during the present study are available from the corresponding author upon reasonable request. 


\section{Authors' contributions}

BS and MS contributed to the experimental design and fundraising. YZ and YX performed some of the expriments. RZ and LG assisted in the data analysis. SL analyzed the data and drafted the initial manuscript.

\section{Ethics approval and consent to participate}

This study was approved by the Medical Ethics Committee of The Fourth Hospital of Hebei Medical University (Shijiazhuang, China; approval no. 2011KY112). Written informed consent was provided by all participants before enrollment.

\section{Patient consent for publication}

Not applicable.

\section{Competing interests}

The authors declare that they have no competing interests.

\section{References}

1. Wang DS, Pan CC, Lai HC and Huang JM: Expression of HMGA1 and ezrin in laryngeal squamous cell carcinoma. Acta Otolaryngol 133: 626-632, 2013.

2. Steuer CE, El-Deiry M, Parks JR, Higgins KA and Saba NF: An update on larynx cancer. CA Cancer J Clin 67: 31-50, 2017.

3. Li Y, Liu J, Hu W, Zhang Y, Sang J, Li H, Ma T, Bo Y, Bai T, Guo $\mathrm{H}$, et al: miR-424-5p promotes proliferation, migration and invasion of laryngeal squamous cell carcinoma. OncoTargets Ther 12: 10441-10453, 2019.

4. Yang Q, Sun J, Ma Y, Zhao C and Song J: LncRNA DLX6-AS1 promotes laryngeal squamous cell carcinoma growth and invasion through regulating miR-376c. Am J Transl Res 11: 7009-7017, 2019.

5. Bonner J, Giralt J, Harari P, Spencer S, Schulten J, Hossain A, Chang SC, Chin S and Baselga J: Cetuximab and radiotherapy in laryngeal preservation for cancers of the larynx and hypopharynx: A secondary analysis of a randomized clinical trial. JAMA Otolaryngol Head Neck Surg 142: 842-849, 2016.

6. Nishimura G, Sano D, Arai Y, Hatano T, Takahashi H, Tanabe T, Wada T, Morishita D and Oridate N: A prospective clinical trial of the second-look procedure for transoral surgery in patients with T1 and T2 laryngeal, oropharyngeal, and hypopharyngeal cancer. Cancer Med 8: 7197-7206, 2019.

7. Nishimura G, Sano D, Yabuki K, Arai Y, Chiba Y, Tanabe T and Oridate N: The second-look procedure for transoral videolaryngoscopic surgery for T1 and T2 laryngeal, oropharyngeal, and hypopharyngeal cancer patients: Protocol for a nonrandomized clinical trial. JMIR Res Protoc 6: e235, 2017.

8. Strieth S, Ernst BP, Both I, Hirth D, Pfisterer LN, Künzel J and Eder K: Randomized controlled single-blinded clinical trial of functional voice outcome after vascular targeting KTP laser microsurgery of early laryngeal cancer. Head Neck 41: 899-907, 2019.

9. van der Bruggen $\mathrm{P}$, Traversari $\mathrm{C}$, Chomez $\mathrm{P}$, Lurquin $\mathrm{C}$, De Plaen E, van den Eynde B, Knuth A and Boon T: A gene encoding an antigen recognized by cytolytic $\mathrm{T}$ lymphocytes on a human melanoma. Science 254: 1643-1647, 1991.

10. Meek DW and Marcar L: MAGE-A antigens as targets in tumour therapy. Cancer Lett 324: 126-132, 2012.

11. Sang M, Lian Y,Zhou X and Shan B: MAGE-A family: Attractive targets for cancer immunotherapy. Vaccine 29: 8496-8500, 2011.

12. Sang M, Wang L, Ding C, Zhou X, Wang B, Wang L, Lian Y and Shan B: Melanoma-associated antigen genes - an update. Cancer Lett 302: 85-90, 2011.

13. De Plaen E, Arden K, Traversari C, Gaforio JJ, Szikora JP, De Smet C, Brasseur F, van der Bruggen P, Lethé B, Lurquin C, et al: Structure, chromosomal localization, and expression of 12 genes of the MAGE family. Immunogenetics 40: 360-369, 1994.
14. Lian Y, Sang M, Ding C, Zhou X, Fan X, Xu Y, Lü W and Shan B: Expressions of MAGE-A10 and MAGE-A11 in breast cancers and their prognostic significance: A retrospective clinical study. J Cancer Res Clin Oncol 138: 519-527, 2012.

15. Lydiatt WM, Patel SG, O'Sullivan B, Brandwein MS, Ridge JA, Migliacci JC, Loomis AM and Shah JP: Head and neck cancers-major changes in the American Joint Committee on Cancer eighth edition cancer staging manual. CA Cancer J Clin 67: 122-137, 2017.

16. Kalluri R and Weinberg RA: The basics of epithelial-mesenchymal transition. J Clin Invest 119: 1420-1428, 2009.

17. Fidler IJ: The relationship of embolic homogeneity, number, size and viability to the incidence of experimental metastasis. Eur J Cancer 9: 223-227, 1973.

18. Liotta LA, Saidel MG and Kleinerman J: The significance of hematogenous tumor cell clumps in the metastatic process. Cancer Res 36: 889-894, 1976.

19. Batth IS, Mitra A, Rood S, Kopetz S, Menter D and Li S: CTC analysis: An update on technological progress. Transl Res 212: 14-25, 2019

20. Zhang L, Riethdorf S, Wu G, Wang T, Yang K, Peng G, Liu J and Pantel K: Meta-analysis of the prognostic value of circulating tumor cells in breast cancer. Clin Cancer Res 18: 5701-5710, 2012.

21. Bidard FC, Peeters DJ, Fehm T, Nolé F, Gisbert-Criado R, Mavroudis D, Grisanti S, Generali D, Garcia-Saenz JA, Stebbing J, et al: Clinical validity of circulating tumour cells in patients with metastatic breast cancer: A pooled analysis of individual patient data. Lancet Oncol 15: 406-414, 2014.

22. de Bono JS, Scher HI, Montgomery RB, Parker C, Miller MC, Tissing H, Doyle GV, Terstappen LW, Pienta KJ and Raghavan D: Circulating tumor cells predict survival benefit from treatment in metastatic castration-resistant prostate cancer. Clin Cancer Res 14: 6302-6309, 2008.

23. Cohen SJ, Punt CJ, Iannotti N, Saidman BH, Sabbath KD, Gabrail NY, Picus J, Morse M, Mitchell E, Miller MC, et al: Relationship of circulating tumor cells to tumor response, progression-free survival, and overall survival in patients with metastatic colorectal cancer. J Clin Oncol 26: 3213-3221, 2008.

24. Krebs MG, Sloane R, Priest L, Lancashire L, Hou JM, Greystoke A, Ward TH, Ferraldeschi R, Hughes A, Clack G, et al: Evaluation and prognostic significance of circulating tumor cells in patients with non-small-cell lung cancer. J Clin Oncol 29: 1556-1563, 2011

25. Hou JM, Krebs MG, Lancashire L, Sloane R, Backen A, Swain RK, Priest LJ, Greystoke A, Zhou C, Morris K, et al: Clinical significance and molecular characteristics of circulating tumor cells and circulating tumor microemboli in patients with small-cell lung cancer. J Clin Oncol 30: 525-532, 2012.

26. Balic M, Lin H, Williams A, Datar RH and Cote RJ: Progress in circulating tumor cell capture and analysis: Implications for cancer management. Expert Rev Mol Diagn 12: 303-312, 2012.

27. van de Stolpe A, Pantel K, Sleijfer S, Terstappen LW and den Toonder JM: Circulating tumor cell isolation and diagnostics: Toward routine clinical use. Cancer Res 71: 5955-5960, 2011.

28. Savino M, Garrubba M, Parrella P, Baorda F, Copetti M, Murgo R, Zelante L, Carella M, Valori VM and Santini SA: Development of real-time quantitative reverse transcription-PCR for Her2 detection in peripheral blood from patients with breast cancer. Clin Chim Acta 384: 52-56, 2007.

29. Stutterheim J, Ichou FA, den Ouden E, Versteeg R, Caron HN, Tytgat GA and van der Schoot CE: Methylated RASSF1a is the first specific DNA marker for minimal residual disease testing in neuroblastoma. Clin Cancer Res 18: 808-814, 2012.

30. Zhang Y, Wang F, Ning N, Chen Q, Yang Z, Guo Y, Xu D, Zhang D, Zhan T and Cui W: Patterns of circulating tumor cells identified by CEP8, CK and CD45 in pancreatic cancer. Int J Cancer 136: 1228-1233, 2015.

31. Yoon SO, Kim YT, Jung KC, Jeon YK, Kim BH and Kim CW: TTF-1 mRNA-positive circulating tumor cells in the peripheral blood predict poor prognosis in surgically resected non-small cell lung cancer patients. Lung Cancer 71: 209-216, 2011.

32. Gervasoni A, Sandri MT, Nascimbeni R, Zorzino L, Cassatella MC, Baglioni L, Panigara S, Gervasi M, Di Lorenzo D and Parolini O: Comparison of three distinct methods for the detection of circulating tumor cells in colorectal cancer patients. Oncol Rep 25: 1669-1703, 2011.

33. Kim DD, Yang CS, Chae HD, Kwak SG and Jeon CH: Melanoma antigen-encoding gene family member A1-6 and hTERT in the detection of circulating tumor cells following CD45- depletion and RNA extraction. Oncol Lett 14: 837-843, 2017. 
34. Liu S, Sang M, Xu Y, Gu L, Liu F and Shan B: Expression of MAGE-A1,-A9,-A11 in laryngeal squamous cell carcinoma and their prognostic significance: A retrospective clinical study. Acta Otolaryngol 136: 506-513, 2016.

35. Trippel A, Halling F, Heymann P, Ayna M, Al-Nawas B and Ziebart T: The expression of melanoma-associated antigen A (MAGE-A) in oral squamous cell carcinoma: An evaluation of the significance for tumor prognosis. Oral Maxillofac Surg 23: 343-352, 2019.

36. Poojary M, Jishnu PV and Kabekkodu SP: Prognostic value of melanoma-associated antigen-A (MAGE-A) gene expression in various human cancers: A systematic review and meta-analysis of 7428 patients and 44 studies. Mol Diagn Ther: doi.org/10.1007/ s40291-020-00476-5.

37. Elston CW and Ellis IO: Pathological prognostic factors in breas cancer. I. The value of histological grade in breast cancer: Experience from a large study with long-term follow-up. Histopathology 19: 403-410, 1991.

38. Stemke-Hale K, Hennessy B, Mills GB and Mitra R: Molecular screening for breast cancer prevention, early detection, and treatment planning: Combining biomarkers from DNA, RNA, and protein. Curr Oncol Rep 8: 484-491, 2006.
39. Sang M, Wu X, Fan X, Sang M, Zhou X and Zhou N: Multiple MAGE-A genes as surveillance marker for the detection of circulating tumor cells in patients with ovarian cancer. Biomarkers 19: 34-42, 2014.

40. Hart CD, Galardi F, Luca FD, Pestrin M and Di Leo A: Circulating tumour cells as liquid biopsy in breast cancer-advancing from prognostic to predictive potential. Curr Breast Cancer Rep 7: 53-58, 2015.

41. Qiao YY, Lin KX, Zhang Z, Zhang DJ, Shi CH, Xiong M, Qu XH and Zhao XH: Monitoring disease progression and treatment efficacy with circulating tumor cells in esophageal squamous cell carcinoma: A case report. World J Gastroenterol 21: 7921-7928, 2015.

42. Marusyk A, Almendro V and Polyak K: Intra-tumour heterogeneity: A looking glass for cancer? Nat Rev Cancer 12: 323-334, 2012.

43. Krawczyk N, Meier-Stiegen F, Banys M, Neubauer H, Ruckhaeberle E and Fehm T: Expression of stem cell and epithelial-mesenchymal transition markers in circulating tumor cells of breast cancer patients. BioMed Res Int 2014: 415721-415731, 2014. 